\section{In defence of the MRC}

SIR-In view of Professor Roy Calne's letter (Nature 347, 418; 1990), I must make it absolutely clear that the decision to discontinue funding for the MRC Medical Cryobiology Group was a peer review judgement. It was the council's Cell Board that reached the view that the work reported and proposed fell short of the current competitive standard and which decided to recommend that the group should be disbanded. This recommendation was subsequently endorsed by the council itself. As I explained in my earlier letter (Nature 347, 116; 1990), at each stage of the peer review process a wider scientific perspective is introduced and research boards have always had to take account of how the quality of work in one field compares with that in another.

If we were to avoid taking these hard decisions by, as Calne suggests, "spreading the hardship evenly", the end result would be that no research team was properly funded and questions of priority were never addressed. I do not believe that this would be in the interests of UK science.

\section{Medical Research Council, 20 Park Crescent, London W1N 4AL}

SIR-P. J. Barnard's letter (Nature 347, $324 ; 1990$ ) is so misleading that I feel obliged to respond.

In February 1989 , the Secretary of State for Education and Science agreed increases of the order of $£ 20$ million a year in the Medical Research Council (MRC)'s parliamentary grant-in-aid for the years 1989-90, 1990-91 and 1991-92. At the an extension of the council's AIDS Directed Programme beyond the three years originally approved. The $£ 20$ million a year was an increase of about 12 per cent cent quoted by Barnard. Most of this additional $£ 20$ million was earmarked for specific new developments, such as Interdisciplinary Research Centres and the Human Genome Mapping Project.

In the financial year 1990-91, we have received a further $£ 3.3$ million which is not earmarked. But, with pay inflation running at some 9 per cent, the council is having to find about $£ 11$ million a year to meet the additional costs of paying its staff and of salaries paid under grants.

Barnard also refers to the council's decision to close the Molecular Neurobiology Unit on her husband's retirement as director. She does not refer to the council's decision, at the same meeting to see whether a leader of high scientific standing could be recruited to lead a new prosame time, he agreed to provide funds for - a welcome figure, but not the 53 per gramme in the field of molecular neurobiology. If that were possible, the precise organizational relationships of the new team within the MRC would be a matter for negotiation and dependent on requirements for scientific support and collaboration. The council endorsed the Neurosciences Board's hope that there would be opportunities for working in close association with teams in the Laboratory of Molecular Biology.

These longer-term plans for supporting the field of molecular neurobiology are in no way affected by the decision to withdraw resources early from the existing unit in order to help fund some high quality programme and project grant applications that would otherwise have been declined. The savings are being targeted on those sections of the unit that were judged as less competitive following peer review.

NICK WINTERTON

Medical Research Council,

(Head of Secretariat)

20 Park Crescent,

London WIN 4AL, UK

\section{BSE susceptibility}

SIR-Our paper on the inheritance of susceptibility to bovine spongiform encephalopathy (BSE) in pedigree Holstein Friesian cattle (Veterinary Record 126, $5-8 ; 1990)$ is relevant to the question raised by your correspondent $\mathrm{O}$. $\mathrm{H}$. G. Sparrow (Nature 346,694; 1990) as to whether BSE is gene-linked.

Our findings relate to the six-generation pedigrees of $14 \mathrm{BSE}$-affected cows and 14 cows drawn at random from a multiplecase herd and also compared the number of sires and maternal grandsires of the affected cows with 200 samples of 14 randomly drawn unaffected cows per sample from the same herd. The sixgeneration pedigree showed a similar pattern of occurrence of five bulls and their combinations in both BSE-affected and control groups. The nine sires and eight maternal grandsires of the BSE. affected cows were comparable with the modal number of nine sires and nine maternal grandsires in the 200 samples and were therefore as would be expected solely on the basis of the breeding structure of the herd. Forty-four (73 per cent) of the 60 BSE-affected cows were familial in origin with first or second degree relatives with the disease. A study of family pedigrees over three or four generations of 43 BSE-affected cows and one BSEaffected bull showed that one cow and 11 bulls were the heads of families. In the largest family group, with nine BSE cases, the head of the family was an imported Holstein cow.

These heads of families were all of
Canadian Holstein or Dutch Friesian heredity. The fact that no single common ancestor could be incriminated in the Holstein Friesian breed as transmitting BSE, that BSE was diagnosed in other breeds and crossbred animals within a relatively short period after it occurred in the Holstein Friesian and that similar encephalopathies have occurred in other related species such as antelopes within this period suggests that susceptibility to the disease and not the disease itself is inherited.

In a study supported by the Ministry of Agriculture, Fisheries and Food (MAFF) we are now analysing in more detail an extensive set of records of pedigree herds provided by the Holstein Friesian Society of Great Britain and Ireland (HFS). Using information provided by MAFF Central Veterinary Laboratory, Weybridge, on confirmed cases and feeding regimes, we are investigating the extent to which the susceptibility of cattle to BSE may be

44A Berkeley Avenue,

W. V.S. WIJERATNE

Reading,

Berkshire RG1 6JE, UK

R. N. CURNOW

Department of Applied Statistics,

University of Reading,

Whiteknights,

Reading,

Berkshire RG6 2AN, UK

\section{Hunger strike}

SIR-Your readers should know that Victor Ambartzumian, one of the most distinguished astronomers of this century, the former president of the International Council of Scientific Unions and International Astronomical Union, and present president of the Academy of Sciences of Armenia, has begun a political hunger strike in Moscow. The 82-year-old scientist has thus joined the well-known writer Zori Balayan whose hunger strike began on 10 September. The two members of the Soviet Supreme Council are protesting against the violation of human rights in the mountainous Karabagh Armenian region of Azerbaijan. For the third year, this region is under total economic, communications and information blockade, with the result that the problem is widely represented as an ethnic or even religious problem. But, as has often been stressed by the late Andrei Sakharov, the problem of Karabagh is a problem of elementary human rights and discrimination against Armenians.

The time has come for the international scientific community to protest strongly at these terrible circumstances.

Yerevan Physics Institute,

V. GURZADYAN inherited.

Armenia,

NATURE · VOL $347 \cdot 18$ OCTOBER 1990 